\title{
Belt Uniform Sowing Pattern Boosts Yield of Different Winter Wheat Cultivars in Southwest China
}

\author{
Ting Chen ${ }^{1,+}$, Yonghe Zhu ${ }^{2,+}+\mathbb{C}$, Rui Dong ${ }^{3}$, Minjian Ren ${ }^{1}$, Jin He ${ }^{1, *}$ and Fengmin $\mathrm{Li}^{2}{ }^{2}$ \\ 1 The Key Laboratory of Plant Resource Conservation and Germplasm Innovation in Mountainous \\ Region (Ministry of Education), College of Agriculture, Guizhou University, Guiyang 550025, China; \\ chenting9495@163.com (T.C.); rmj72@163.com (M.R.) \\ 2 College of Agriculture, Nanjing Agricultural University, Nanjing 210095, China; yhz@njau.edu.cn (Y.Z.); \\ fmli@lzu.edu.cn (F.L.) \\ 3 College of Zoology, Guizhou University, Guiyang 550025, China; rdong@gzu.edu.cn \\ * Correspondence: hejin0811@163.com \\ + These authors contributed equally to this work.
}

check for

updates

Citation: Chen, T.; Zhu, Y.; Dong, R.; Ren, M.; He, J.; Li, F. Belt Uniform Sowing Pattern Boosts Yield of Different Winter Wheat Cultivars in Southwest China. Agriculture 2021, 11, 1077. https://doi.org/10.3390/ agriculture11111077

Received: 4 September 2021

Accepted: 27 October 2021

Published: 1 November 2021

Publisher's Note: MDPI stays neutral with regard to jurisdictional claims in published maps and institutional affiliations.

Copyright: (c) 2021 by the authors. Licensee MDPI, Basel, Switzerland. This article is an open access article distributed under the terms and conditions of the Creative Commons Attribution (CC BY) license (https:// creativecommons.org/licenses/by/ $4.0 /)$.

\begin{abstract}
The relationship between the sowing patterns and yield performance is a valuable topic for food security. In this study, a novel belt uniform (BU) sowing pattern was reported, and a field experiment with four winter wheat cultivars was carried out over three consecutive growing seasons to compare the dry matter accumulation, harvest index (HI), grain yield and yield components under $\mathrm{BU}$ and line and dense (LD) sowing patterns [BU sowing with narrow $(15 \mathrm{~cm})$ spacing; BU sowing with wide $(20 \mathrm{~cm})$ spacing; LD sowing with wide $(33.3 \mathrm{~cm})$ row spacing; LD sowing with narrow $(16.6 \mathrm{~cm})$ row spacing]. Four cultivars produced a higher mean grain yield (GY), above-ground biomass (AGB) and spike number (SN) per $\mathrm{m}^{2}$ under the BU sowing patterns than the LD sowing patterns in all three growing seasons. However, yield stability under the BU sowing patterns did not increase with the improved grain yield. The HI did not change with sowing patterns, and the contribution of above-ground biomass to grain yield ( $84 \%$ ) was more than 5-fold higher than that of HI (16\%). Principal component and correlation analyses indicated that the grain yield was positively correlated with the aboveground biomass and SN, while the HI and 1000-grain weight were not correlated with grain yield. We concluded that (1) the novel BU sowing patterns achieved a higher yield potential in winter wheat but did not further improve yield stability; (2) increasing the dry matter accumulation without changing the $\mathrm{HI}$ drove improvements in the SN and grain number per spike, thus increasing grain yield.
\end{abstract}

Keywords: sowing pattern; winter wheat; biomass; grain yield; harvest index

\section{Introduction}

Wheat is one of the most important cereal crops grown worldwide [1] and the third most important staple crop in China. The yield improvement in winter wheat was realized by improving the harvest index (HI) [2-4], dry matter accumulation and radiation use efficiency [5-9]. Increasing the HI is the main driver of yield improvements through wheat breeding $[5,7,10]$. Although the theoretical limit of the HI is 0.62 for wheat [11], HI values have not progressed since the 1990s when they reached $\sim 0.50-0.55$ [5]. Thus, it is difficult to further improve yield by raising the $\mathrm{HI}$, because this has reached a realistic limit of $\sim 0.5$ [5,7]. Future yield improvement should rely on achieving greater above-ground biomass (AGB), while at least maintaining present HI levels [7]. The relative contribution of the AGB and HI to the grain yield was not well known.

Most studies concentrated on the role of fertilizer schemes and planting density in yield performance [12,13], but previous studies showed new sowing patterns such as raisedbed sowing [14] and furrow sowing [15] could increase the yields of winter wheat [16,17] and other crops $[18,19]$. Li et al. $[15,20]$ reported a wide and narrow furrow planting 
which could increase the winter wheat grain yield in the North China Plain. Recently, a new sowing method-wide-precision planting pattern (sowing width was $6-8 \mathrm{~cm}$ ) was reported; the author proposed that this new method, combined with deficit irrigation, could maximize winter wheat production in the North China Plain [20]. Thus, the development of new cultivation measures contributes hugely to increasing winter wheat yields. Moreover, previous studies have shown yield improvements associated with increases in radiation use efficiency [6], biomass [8,9] and spike number (SN) per square meter [20,21].

South China is one of the three main winter wheat production areas in China [10]. In this study, we reported a novel sowing pattern and the yield; yield components and biomass accumulation were compared among four sowing patterns and identified the related contribution of the HI and AGB to yield performance. The following hypotheses were tested: (1) the novel sowing pattern could improve the winter wheat grain yield, which was associated with the increasing of AGB not HI; (2) the yield improvement was associated with the increasing of the spike number $\mathrm{m}^{-2}(\mathrm{SN})$, grain number per spike (GN) or 1000-grain weight (TGW).

\section{Materials and Methods}

\subsection{Materials and Growth Conditions}

A field experiment was conducted in the Guiyang, Guizhou province, China. The mean temperatures were $10.2,9.5$ and $11.0^{\circ} \mathrm{C}$, whereas the precipitation was 377,316 and $367 \mathrm{~mm}$ for the 2017-2018, 2018-2019 and 2019-2020 growing seasons, respectively (Figure 1). The soil in the field was classified as yellow soil according to the Chinese soil classification system. The soil organic matter and soil available $\mathrm{P}, \mathrm{N}$ and $\mathrm{K}$ were $6.60 \mathrm{~g} \mathrm{~kg}^{-1}$, $4.85 \mathrm{mg} \mathrm{kg}^{-1}, 31.50 \mathrm{mg} \mathrm{kg}^{-1}$, and $141.69 \mathrm{mg} \mathrm{kg}^{-1}$ in 2017, respectively.
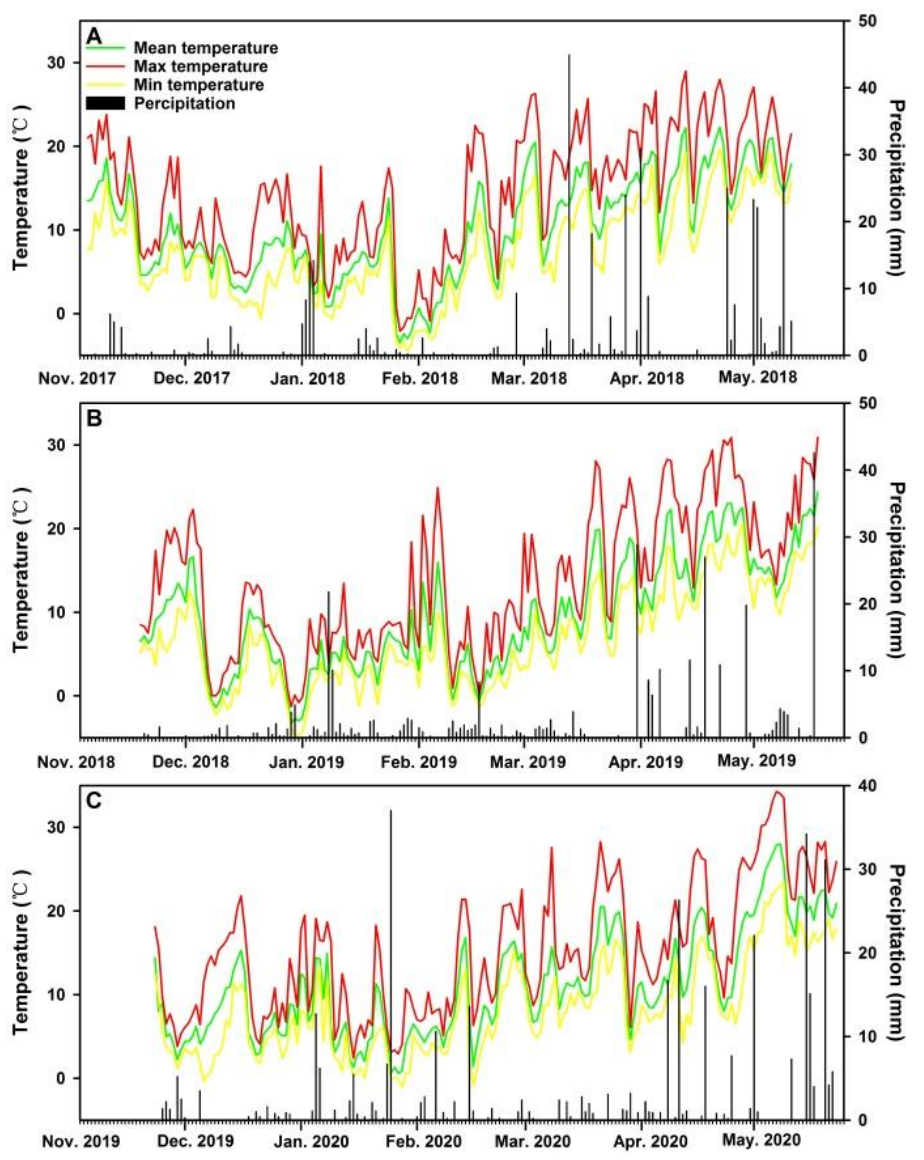

Figure 1. The daily mean, maximum and minimal temperature and daily precipitation during the experiment in (A) 2017-2018, (B) 2018-2019 and (C) 2019-2020. 
Four sowing patterns (Line and dense (LD) sowing with wide $(33.3 \mathrm{~cm}$ ) row spacing (LDW, conventional sowing pattern); Line and dense (LD) sowing with narrow $(16.6 \mathrm{~cm})$ row spacing $(\mathrm{LDN})$; Belt uniform $(\mathrm{BU})$ sowing with narrow $(15 \mathrm{~cm})$ row spacing $(\mathrm{BUN})$; and Belt uniform (BU) sowing with wide $(20 \mathrm{~cm})$ row spacing $(\mathrm{BUW}))$ were used in this study (Figure 2). Four wheat cultivars (Guinong 19 (G19); Guinong 30 (G30); Guizi 1 (G1); and Guizi 4 (G4)) were used in three consecutive years during the winter wheat growing season. G19 and G30 were common cultivars; G1 and G4 were high anthocyanin (about $50 \mathrm{mg} \mathrm{kg}^{-1}$ ) winter wheat cultivars. A completely random experimental design was used in this study and there were three replicates per cultivar per sowing pattern, the area of each plot was $4 \mathrm{~m}^{2}(2 \mathrm{~m} \times 2 \mathrm{~m})$. The plant density was 225 plants per $\mathrm{m}^{2}$. Before sowing, $160 \mathrm{~kg} \mathrm{~N} \mathrm{ha}^{-1}, 35 \mathrm{~kg} \mathrm{P} \mathrm{ha}^{-1}$ and $35 \mathrm{~kg} \mathrm{~K} \mathrm{ha}^{-1}$ were applied according to local practice. Pesticides were used when necessary and the weeds were controlled by hand. The sowing and harvest dates were November 5 in 2017 and May 11 in 2018 for the 2017-2018 growing season, November 19 in 2018 and May 18 in 2019 for the 2018-2019 growing season, and November 23 in 2019 and May 23 in 2020 for the 2019-2020 growing season.
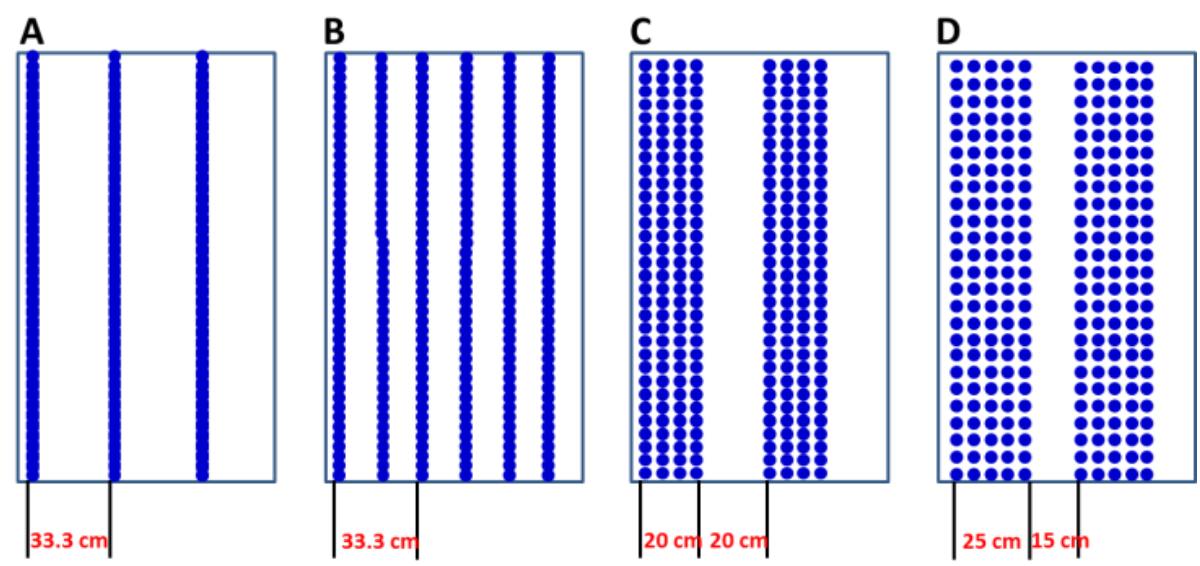

Figure 2. The four sowing patterns (A): Line and dense sowing with wide $(33.3 \mathrm{~cm})$ row space (LDW). (B): Line and dense sowing with narrow $(16.6 \mathrm{~cm})$ row space $(\mathrm{LDN})$. (C): belt uniform sowing with wide $(20 \mathrm{~cm})$ row space (BUN). (D): belt uniform sowing with narrow $(15 \mathrm{~cm})$ row space $(B U W)$ used in this study. All sowing patterns have the same seed rate.

\subsection{Harvest and Measurement of Parameters}

When the winter wheat reached maturity, two rows in the center were harvested. The shoots were cut about $1 \mathrm{~cm}$ above the soil surface, placed in nylon bags, tagged and transported to the lab for further measurement.

The spikes were cut from the shoots, and the leaf and stem were combined and dried at $80^{\circ} \mathrm{C}$ for $48 \mathrm{~h}$; then, the dry weights of the spike and the leaf + stem were evaluated. The dry weight was obtained by adding together the dry weights of the spike, leaf and stem. The number of spikes was counted for each sample in each plot; then, a subsample (ten representative spikes) was chosen to determine the grain numbers for each spike. The remaining spikes were threshed to obtain the grains and those were combined with the grains of the sub-samples to determine the grain yield for each plot. The grain yield $\left(\mathrm{g} \mathrm{m}^{-2}\right)$ was obtained by dividing the grain yield for each sample for each plot by the harvested area. The harvest index $(\mathrm{HI}, \%)=($ grain yield $\times 100) /$ AGB .

\subsection{Statistics Analysis}

A two-way analysis of variance (ANOVA) for each year was conducted using GenStat 19.0 (VSN International Ltd., Rothamsted, UK) to analyze the effects of sowing patterns and cultivars and their interaction on the grain yield, yield components and biomass accumulation. Principal component analysis (PCA) was also conducted using GenStat 19.0, based on grain yield, yield formation traits and yield components. All figures were 
generated using Origin 2020 (Origin Lab, Northampton, MA, USA); the elements of yield formation are presented using a histogram, the relationships are shown using a scatter plot and the stability of each cultivar in different sowing patterns is presented using a bubble chart.

The data for AGB, $\mathrm{HI}$ and grain yield were combined and used to evaluate the contribution of AGB and $\mathrm{HI}$ to winter wheat grain yield as follows:

$$
\begin{gathered}
\mathrm{A}_{1}=\mathrm{B}_{1} \mathrm{~S}_{\mathrm{X} 1} / \mathrm{S}_{\mathrm{Y}} ; \mathrm{B}_{1}=\mathrm{B}_{2} \mathrm{~S}_{\mathrm{X} 2} / \mathrm{S}_{\mathrm{GY}} \\
\mathrm{C}_{\mathrm{AGB}}=\left(\mathrm{A}_{1} /\left(\mathrm{A}_{1}+\mathrm{B}_{1}\right)\right) \times 100 \% ; \mathrm{C}_{\mathrm{HI}}=\left(\mathrm{B}_{1} /\left(\mathrm{A}_{1}+\mathrm{B}_{1}\right)\right) \times 100 \%
\end{gathered}
$$

where $A_{1}$ and $B_{1}$ represent the standardized coefficients of $A G B$ and $H I ; B_{1}$ and $B_{2}$ represent the coefficients of $\mathrm{AGB}$ and $\mathrm{HI}$ in the partial regression equation; and $\mathrm{S}_{\mathrm{X} 1}, \mathrm{~S}_{\mathrm{X} 2}$ and $\mathrm{S}_{\mathrm{GY}}$ represent the standard deviation of $\mathrm{AGB}, \mathrm{HI}$ and grain yield, respectively. The contributions of $\mathrm{AGB}$ and $\mathrm{HI}$ to grain yield are represented by $\mathrm{C}_{\mathrm{AGB}}$ and $\mathrm{C}_{\mathrm{HI}}$.

\section{Results}

\subsection{Yield Performance}

The HI was significantly related to the genotypes of the wheat, but its effect on the AGB and grain yield (GY) was irregular. The sowing pattern significantly affected the AGB, $\mathrm{HI}$ and grain yield, and the interaction with genotype significantly influenced the AGB, $\mathrm{HI}$ and grain yield during the 2017-2018 and 2018-2019 growing seasons (Table 1). Each cultivar produced the highest yield under the BU sowing conditions (Table 1; Figure 3A-C). Compared with the LDN sowing pattern, the average yield and AGB under the BU patterns was nearly double (Figure 3). The HI did not change with the sowing pattern but the AGB was significantly increased under the BU patterns (Figure 3). The contribution of AGB to yield $(84 \%)$ was more than five-fold higher than that of $\mathrm{HI}(16 \%$; Table 2$)$.

Table 1. The above-ground biomass (AGB, $\mathrm{g} \mathrm{m}^{-2}$ ), harvest index (HI, \%) and grain yield (GY, $\mathrm{g} \mathrm{m}^{-2}$ ) and their means of four wheat genotypes under four different sowing patterns during three consecutive growing seasons. LSD values at

\begin{tabular}{|c|c|c|c|c|c|c|c|c|c|c|c|c|c|}
\hline \multirow{2}{*}{$\begin{array}{c}\text { Genotype } \\
\text { (G) }\end{array}$} & \multirow{2}{*}{$\begin{array}{c}\text { Sowing } \\
\text { Pattern (SP) }\end{array}$} & \multicolumn{3}{|c|}{$2017-2018$} & \multicolumn{3}{|c|}{ 2018-2019 } & \multicolumn{3}{|c|}{ 2019-2020 } & \multicolumn{3}{|c|}{ Means of Three Years } \\
\hline & & AGB & HI & GY & AGB & HI & GY & AGB & HI & GY & AGB & HI & GY \\
\hline \multirow{5}{*}{ G1 } & LDN & 426 & 32.1 & 137 & 489 & 43.9 & 213 & 560 & 43.2 & 241 & 492 & 39.7 & 197 \\
\hline & LDW & 846 & 41.6 & 351 & 611 & 49.1 & 301 & 1065 & 43.1 & 457 & 841 & 44.6 & 370 \\
\hline & BUN & 1098 & 43.5 & 477 & 957 & 44.2 & 430 & 1119 & 45.6 & 510 & 1058 & 44.9 & 472 \\
\hline & BUW & 914 & 40.9 & 374 & 1045 & 46.9 & 489 & 1241 & 44.5 & 552 & 1067 & 44.1 & 472 \\
\hline & G1-means & 821 & 38.2 & 335 & 775 & 46.0 & 358 & 996 & 44.1 & 440 & 864 & 42.8 & 378 \\
\hline \multirow{5}{*}{ G19 } & LDN & 486 & 49.2 & 239 & 538 & 48.8 & 263 & 538 & 45.9 & 249 & 521 & 48.0 & 250 \\
\hline & LDW & 652 & 46.3 & 304 & 450 & 49.5 & 223 & 924 & 49.1 & 453 & 675 & 48.3 & 327 \\
\hline & BUN & 774 & 47.3 & 365 & 868 & 50.6 & 439 & 1170 & 45.9 & 538 & 937 & 47.9 & 447 \\
\hline & BUW & 871 & 49.4 & 431 & 1139 & 45.3 & 516 & 1140 & 47.8 & 545 & 1050 & 47.5 & 497 \\
\hline & G19-means & 696 & 48.1 & 335 & 749 & 48.6 & 360 & 943 & 47.2 & 446 & 796 & 48.0 & 380 \\
\hline \multirow{5}{*}{ G30 } & LDN & 542 & 46.9 & 255 & 718 & 44.8 & 322 & 465 & 43.5 & 203 & 575 & 45.1 & 260 \\
\hline & LDW & 508 & 47.9 & 242 & 662 & 45.5 & 301 & 941 & 48.2 & 455 & 704 & 47.2 & 333 \\
\hline & BUN & 833 & 46.5 & 395 & 986 & 42.0 & 413 & 1296 & 46.6 & 604 & 1038 & 45.1 & 471 \\
\hline & BUW & 758 & 49.4 & 374 & 806 & 44.0 & 349 & 1199 & 46.5 & 558 & 921 & 46.6 & 427 \\
\hline & G30-means & 660 & 47.7 & 317 & 793 & 44.1 & 346 & 975 & 46.2 & 455 & 809 & 45.9 & 373 \\
\hline \multirow{8}{*}{ G4 } & LDN & 584 & 45.8 & 312 & 551 & 48.2 & 266 & 502 & 43.9 & 220 & 546 & 46.0 & 266 \\
\hline & LDW & 760 & 45.9 & 349 & 635 & 46.7 & 295 & 1142 & 45.6 & 521 & 846 & 46.1 & 388 \\
\hline & BUN & 962 & 45.2 & 434 & 916 & 42.4 & 390 & 1291 & 46.7 & 603 & 1056 & 44.8 & 476 \\
\hline & BUW & 849 & 46.7 & 396 & 799 & 44.4 & 355 & 1308 & 48.1 & 629 & 985 & 46.4 & 460 \\
\hline & G4-means & 789 & 45.9 & 373 & 725 & 45.4 & 327 & 1061 & 46.1 & 493 & 858 & 45.8 & 397 \\
\hline & & $* * *(74)$ & $* * *(1.6)$ & & n.s & $* * *(1.4)$ & $*(23)$ & & $* * *(1.1)$ & & & & \\
\hline & SP & $* * *(74)$ & $* *(1.6)$ & $* * *(41)$ & $* * *(56)$ & $* * *(1.4)$ & $* * *(23)$ & $* * *(95)$ & $* * *(1.1)$ & $* * *(46)$ & & & \\
\hline & $\mathrm{G} \times \mathrm{SP}$ & $* *(149)$ & $* * *(3.3)$ & ** (83) & $* * *(111)$ & $* * *(2.9)$ & $* * *(46)$ & n.s & $*(2.3)$ & n.s & & & \\
\hline
\end{tabular}
$p=0.05$ are in parenthesis. n.s not significant, ${ }^{*} p<0.05,{ }^{* *} p<0.01,{ }^{* * *} p<0.001$. 

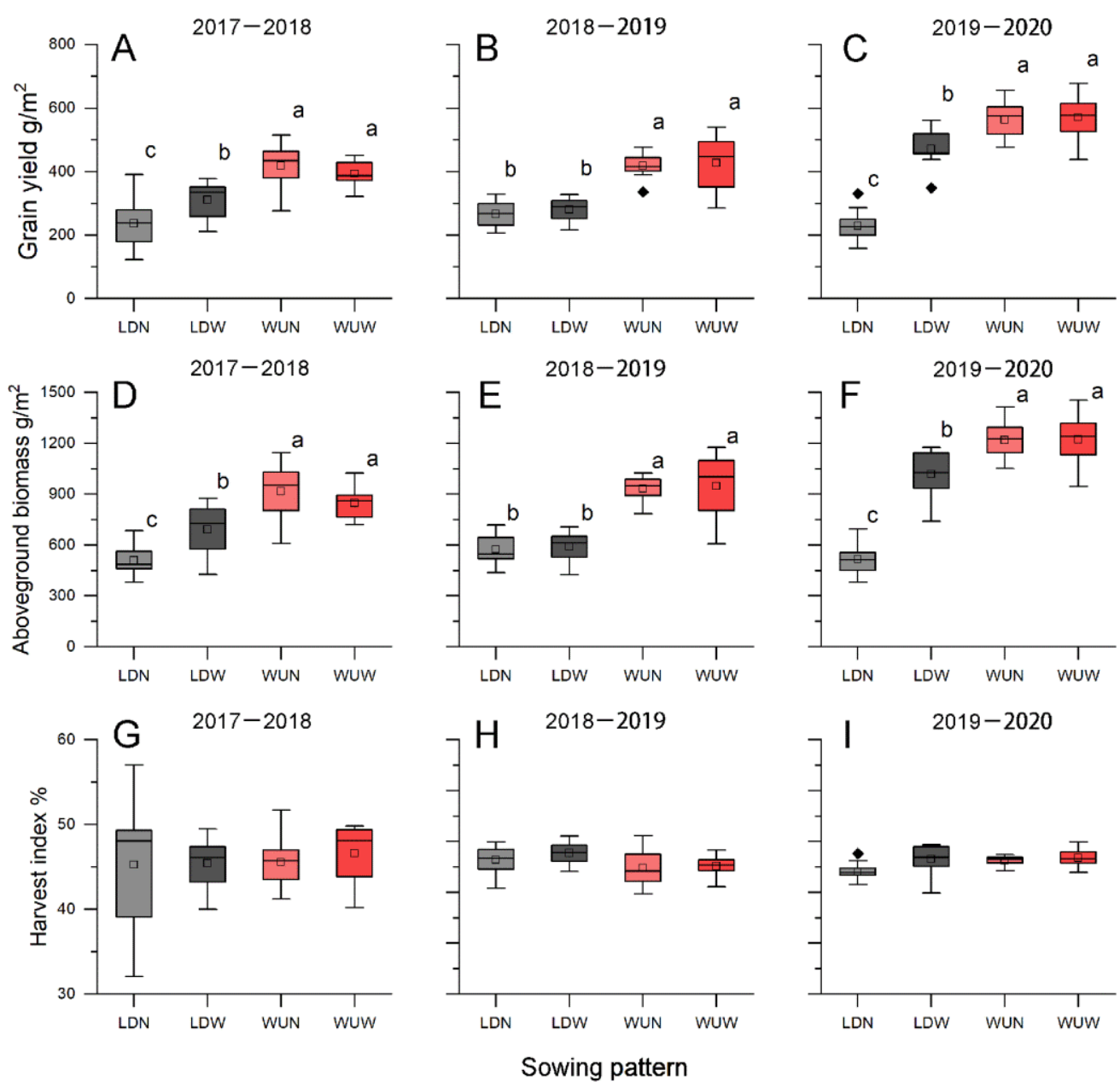

Figure 3. The grain yield (A-C), shoot biomass (D-F) and harvest index (G-I) (HI) of four winter wheat cultivars under four sowing patterns during the growing seasons of 2017-2018, 2018-2019 and 2019-2020. Means \pm SE $(n=3)$ with the different letters in each figure indicating a significant difference at $p=0.05$.

Table 2. The variation in grain yield, above-ground dry biomass (AGB) and harvest index (HI) and the contribution of AGDM and HI to grain yield in winter wheat grown from 2017-2020. ${ }^{* * *} p<0.001$.

\begin{tabular}{cccccccccccc}
\hline \multicolumn{2}{c}{ Grain Yield $\left(\mathrm{g} \mathrm{m}^{-2}\right)$} & \multicolumn{3}{c}{ AGB $\left(\mathrm{g} \mathrm{m}^{-2}\right)$} & \multicolumn{2}{c}{ HI } & \multicolumn{3}{c}{ Contribution Rate to Yield (\%) } \\
\hline Range & Mean & CV (\%) & Range & Mean & CV (\%) & Range & Mean & CV (\%) & AGB & HI \\
\hline $208-744$ & 433 & 34.3 & $401-1630$ & 960 & 34.7 & $0.40-0.62$ & 0.46 & 9.9 & $83.7^{* * *}$ & $16.3^{* * *}$ \\
\hline
\end{tabular}

The yield components were significantly affected by genotype, sowing pattern and their interaction (Table 3). All genotypes had higher SN per unit area in the BU sowing pattern with narrow or wide row spacing (Table 3; Figure 4A-C). The effects on grain number per spike of genotype and sowing pattern were not regular. The genotypes made a regular and significant difference to the 1000-grain weight, however (Figure 4). G4 had the highest 1000-grain weight, followed by G19 and G30, while that of G1 was the lowest (Table 3). 
Table 3. The spike number (SN), grain number (GN) per spike and 1000-grain weight (TGW) of four wheat genotypes under four different sowing patterns during three consecutive growing seasons. LSD values at $p=0.05$ are in parenthesis. n.s not significant, ${ }^{* *} p<0.01,{ }^{* * *} p<0.001$.

\begin{tabular}{|c|c|c|c|c|c|c|c|c|c|c|}
\hline \multirow{2}{*}{$\begin{array}{l}\text { Genotype } \\
\text { (G) }\end{array}$} & \multirow{2}{*}{$\begin{array}{c}\text { Sowing } \\
\text { Pattern (SP) }\end{array}$} & \multicolumn{3}{|c|}{$2017-2018$} & \multicolumn{3}{|c|}{ 2018-2019 } & \multicolumn{3}{|c|}{ 2019-2020 } \\
\hline & & SN & GN & TGW & SN & GN & TGW & SN & GN & TGW \\
\hline \multirow{4}{*}{ G1 } & LDN & 138 & 32.7 & 30.1 & 159 & 44.3 & 30.8 & 157 & 48.4 & 31.6 \\
\hline & LDW & 328 & 35.3 & 30.3 & 234 & 39.1 & 33.2 & 313 & 40.5 & 36.0 \\
\hline & BUN & 398 & 39.2 & 30.9 & 381 & 36.3 & 31.1 & 248 & 65.8 & 31.3 \\
\hline & BUW & 350 & 34.6 & 30.7 & 348 & 43.6 & 32.3 & 370 & 43.9 & 34.0 \\
\hline \multirow{4}{*}{ G19 } & LDN & 177 & 38.4 & 35.2 & 253 & 29.3 & 35.4 & 158 & 43.9 & 35.4 \\
\hline & LDW & 314 & 26.1 & 37.8 & 269 & 23.8 & 34.8 & 260 & 54.3 & 32.1 \\
\hline & BUN & 380 & 27.9 & 34.4 & 279 & 45.7 & 34.4 & 350 & 47.2 & 32.5 \\
\hline & BUW & 352 & 33.7 & 36.5 & 375 & 37.9 & 36.3 & 336 & 44.9 & 36.0 \\
\hline \multirow{4}{*}{ G30 } & LDN & 169 & 44.9 & 33.3 & 214 & 42.3 & 35.6 & 166 & 32.2 & 37.9 \\
\hline & LDW & 221 & 26.8 & 40.8 & 279 & 28.5 & 37.9 & 307 & 36.2 & 40.6 \\
\hline & BUN & 276 & 42.4 & $\begin{array}{l}40.0 \\
33.0\end{array}$ & 390 & 31.6 & 33.8 & 371 & 47.2 & $34.6 \mathrm{~b}$ \\
\hline & BUW & 366 & 31.4 & 33.0 & 376 & 25.5 & 36.2 & 364 & 38.7 & 39.4 \\
\hline \multirow{7}{*}{ G4 } & LDN & 178 & 40.7 & 45.2 & 205 & 29.0 & 45.0 & 129 & 38.0 & 44.9 \\
\hline & LDW & 304 & 28.3 & 40.8 & 243 & 29.1 & 41.8 & 261 & 46.6 & 42.8 \\
\hline & BUN & 343 & 31.7 & 40.8 & 334 & 29.1 & 39.9 & 303 & 50.9 & 39.2 \\
\hline & BUW & 268 & 36.8 & 42.9 & 316 & 27.2 & 41.3 & 311 & 51.1 & 39.7 \\
\hline & G & $* *(26)$ & n.s & $* * *(0.3)$ & $* *(20)$ & $* * *(2.2)$ & $* * *(0.3)$ & $* * *(22)$ & $* * *(2.2)$ & $* * *(0.2)$ \\
\hline & $\mathrm{SP}$ & $* * *(26)$ & $* *(5)$ & $* * *(0.3)$ & $* * *(20)$ & $* * *(2.2)$ & $* * *(0.3)$ & $* * *(22)$ & $* * *(2.2)$ & $* * *(0.2)$ \\
\hline & $\mathrm{G} \times \mathrm{SP}$ & $* * *(52)$ & ** (10) & $* * *(0.5)$ & $* * *(39)$ & $* * *(4.6)$ & $* * *(0.6)$ & $* * *(44)$ & $* * *(4.3)$ & $* * *(0.4)$ \\
\hline
\end{tabular}
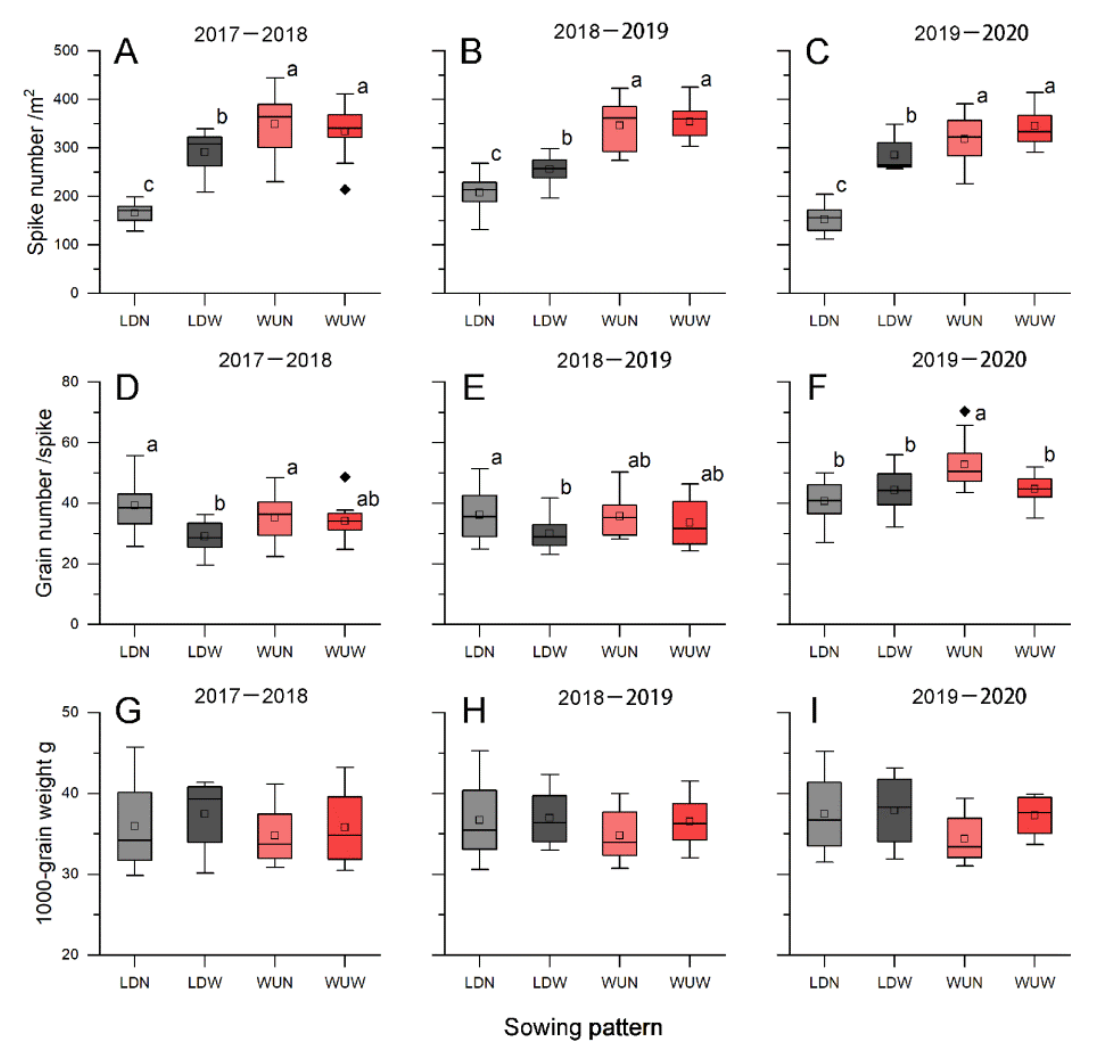

Figure 4. The spike number (A-C), grain number per spike (D-F) and thousand-grain weight (G-I) in four winter wheat cultivars under four sowing patterns during the growing seasons of 2017-2018, 2018-2019 and 2019-2020. Means are \pm SE $(n=3)$ with the different letters in each figure indicating a significant difference at $p=0.05$.

\subsection{Relationships between Yield and Its Components}

The increase in grain yield was significantly positively correlated with the AGB under different sowing patterns $(r=0.98, p<0.001)$. All genotypes produced a higher mean 
AGB and grain yield under the BU sowing patterns than those planted under both the LDW and LDN sowing patterns (Figure 5A). The correlation between SN per unit area and grain yield was the same as between AGB and grain yield ( $r=0.69, p<0.001$; Figure $5 \mathrm{~B})$. However, there was a positive correlation between grain yield and grain number per single spike $(r=0.51, p<0.001)$; the grain number per spike under the BU patterns was not always higher than that under the other patterns and showed an irregular trend (Figure 5C). The HI and 1000-grain weight were not correlated with grain yield and the HI was not significantly different among the four sowing patterns (Figure 5D,E). The mean grain yield across the 3 years was significantly improved by using the new sowing methods, but the yield stability did not increase with the grain yield improvement, except in G9 (Figure 6).
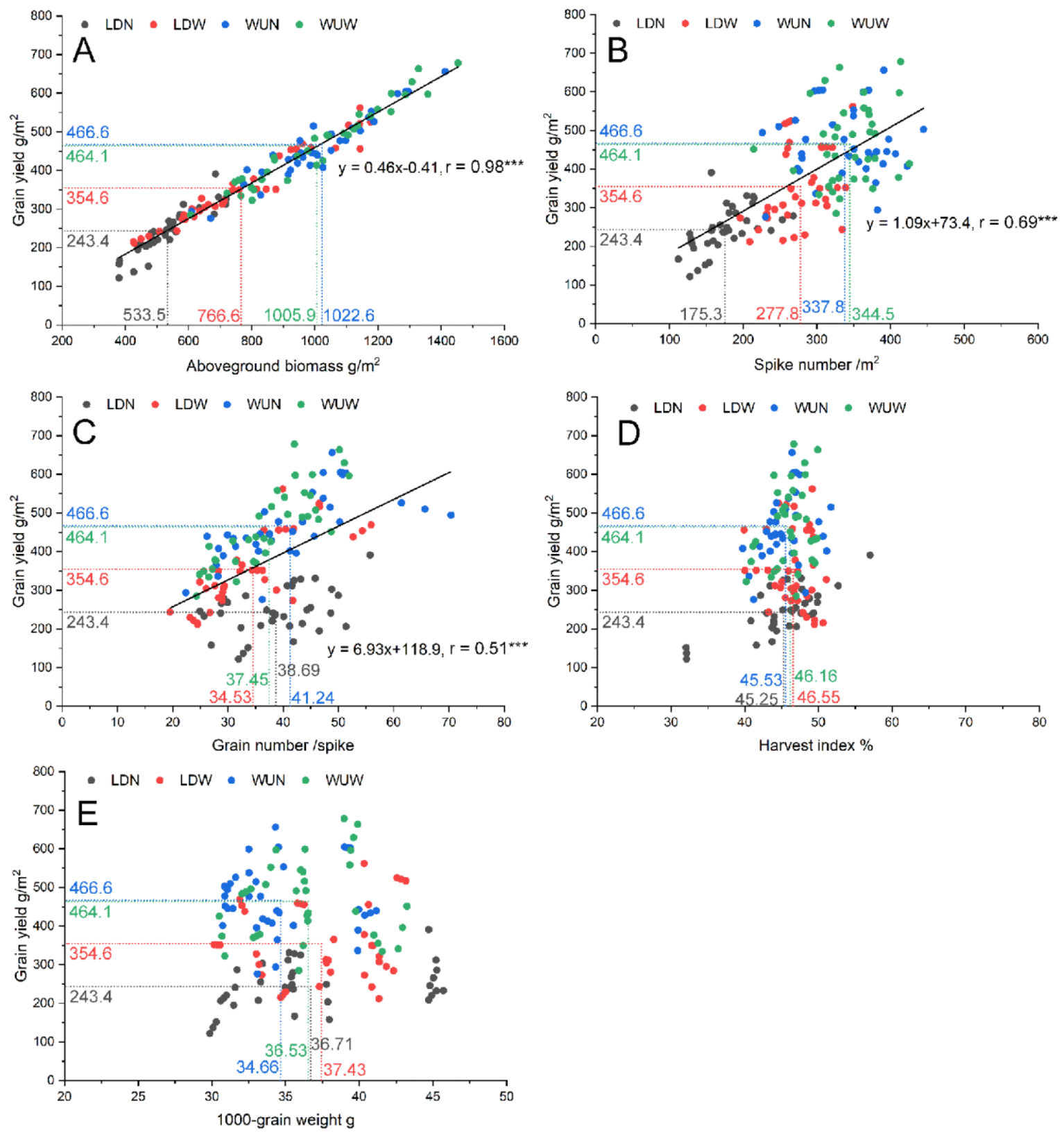

Figure 5. The relationship between the grain yield and (A) above-ground biomass $\left(\mathrm{g} \mathrm{m}^{-2}\right)$, (B) spike number per square meter, (C) grain number per spike, (D) harvest index and (E) 1000-grain weight under four sowing patterns. ${ }^{* * *} p<0.001$. 


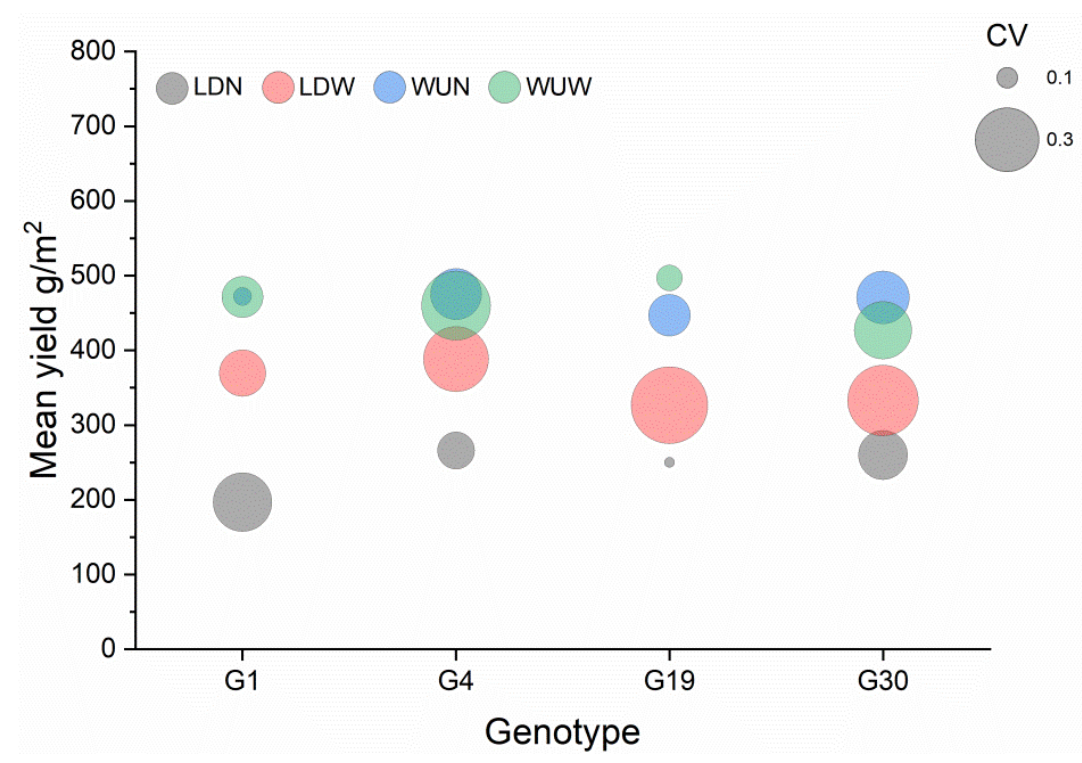

Figure 6. The grain yield and yield stability of four winter wheat cultivars (Guizi 1 (G1), Guizi 4 (G4), Guinong 19 (G19) and Guinong 39 (G30)) under four sowing patterns.

A PCA (Figure 7) based on yield formation traits and yield components indicated that the AGB and SN per $\mathrm{m}^{2}$ highly correlated with PC1 were positively correlated with grain yield. PC2 was correlated with $\mathrm{HI}$ and 1000-grain weight, the inherent features of genotype. The scoring data obtained under the BU sowing patterns were closer to the SN, AGB and yield loadings than the LD conditions.

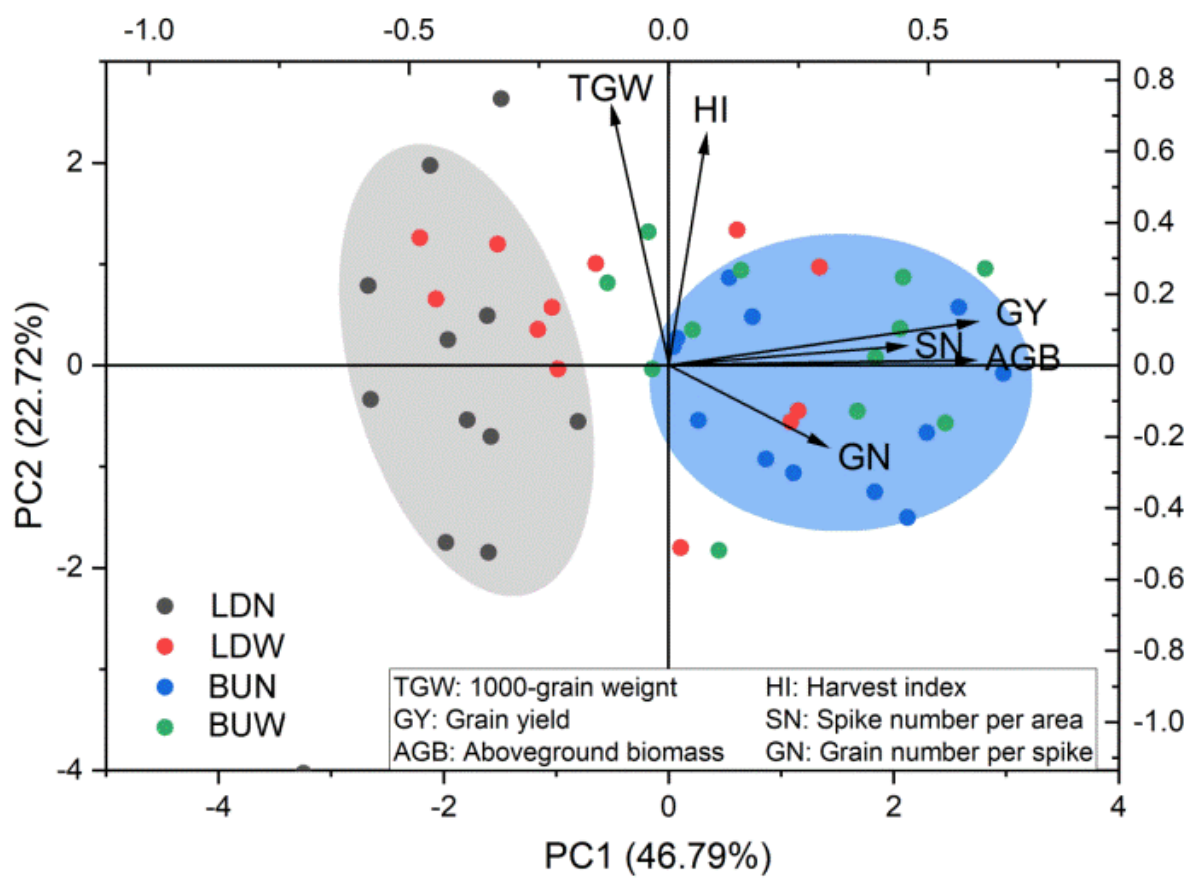

Figure 7. PCA based on yield formation and yield components of winter wheat grown under different sowing patterns during three consecutive growing seasons.

\section{Discussion}

In this study, a novel sowing pattern was reported and this largely improved $29.5 \%$ grain yield across all genotypes and years in Southern China, compared with other sowing methods such as raised bed-sowing (5.2\%) [14], bed sowing (7.0\%) [22] and wide-precision sowing (6.7-12.7\%) [6]. These results not only highlighted the importance of developing 
new sowing methods to increase grain yield but also indicated that the new sowing method implemented in this study vastly improved yield. Moreover, we found no significant differences in the yield obtained from the four winter wheat cultivars under the BU sowing pattern, indicating that these four cultivars had similar yield potentials and the proper sowing methods could help to realize this high yield potential. However, the yield stability did not improve with increases in grain yield in three of the four cultivars. Thus, more work, such as improved fertilizer management, will be required to improve the yield stability [13].

Previous studies showed that yield improvement was associated with increasing radiation use efficiency [6], biomass [8,9], leaf area index [23] and yield components [10,20]. However, in this study, we focused on the response of the biomass and yield components and their roles in yield performance under different sowing patterns. The AGB and HI are the two main factors that determine the grain yield, as indicated by the equation: grain yield $=(\mathrm{AGB} \times \mathrm{HI}) / 100$ [24]. In this study, the biomass increased by $24-38 \%$, while the grain yield increased by $25-34 \%$ under the new sowing patterns; however, the HI was almost the same between the four sowing patterns (0.45-0.48). Moreover, the contribution of the AGB to grain yield was more than five-fold higher than that of HI. These results clearly showed that (1) increasing the biomass was the main driver of grain yield improvement under the BU sowing patterns; (2) it was hard to increase GY by increasing the HI, which was almost 0.5 . Solar radiation is essential for plant growth in field conditions and the leaf area index was the main factor determined the absorb of the solar radiation [6]. Thus, the large amount of biomass may have been a result of an increase in the leaf area index [23], a high radiation interaction ratio and use efficiency $[6,25]$ and higher land use related to narrow row spacing. Reasonable line spacing can improve the space arrangement between the plants and help to increase the radiation interaction ratio and use efficiency [26,27].

Increases in yield components, such as TGW, SN and GN, have been significant in improving yields of winter wheat worldwide $[7,10,28-30]$. In this study, we found that variations in the 1000-grain weight were observed among the different winter wheat cultivars, but this did not contribute to the yield performance, indicating that the 1000-grain weight was a specific property of each cultivar and the sowing patterns had little effect on it. Both the SN per $\mathrm{m}^{2}$ and grain number per spike were positively correlated with yield performance, indicating that these two traits could be altered through breeding and field management in winter wheat. Thus, developing new farming methods combined with the high yield potential winter wheat cultivar could further increase the grain yield [9]. Furthermore, we found that $\mathrm{SN}$ per $\mathrm{m}^{2}$ was more important than grain number per spike in yield performance and a $51 \%$ variation in the $\mathrm{SN}$ per $\mathrm{m}^{2}$ was explained by the high accumulation of biomass. Moreover, changing the row spacing also contributed to increasing the SN per $\mathrm{m}^{2}[26,27]$.

\section{Conclusions}

In this study, the BU sowing patterns significantly increased the grain yield of winter wheat in three consecutive growing seasons; the increasing of aboveground biomass, not the harvest index, was the main driver for the improvement of the grain yield; the increasing of the aboveground biomass was associated with the improvement of the spike number per $\mathrm{m}^{2}$. The fixed traits related to the wheat genotype, such as $\mathrm{HI}$, the grain number per spike, and 1000-grain weight, did not change or had an irregular performance under different sowing patterns.

Author Contributions: Conceptualization, J.H.; Formal analysis, T.C., Y.Z., R.D. and J.H.; Funding acquisition, J.H.; Investigation, T.C. and M.R.; Methodology, T.C. and J.H.; Supervision, F.L.; Writingoriginal draft, T.C., Y.Z. and J.H.; Writing-review \& editing, Y.Z., R.D., M.R., J.H. and F.L. All authors have read and agreed to the published version of the manuscript. 
Funding: This research was supported by National Natural Science Foundation of China (32060427), the Guizhou Science and Technology Support Program Project (Qiankehezhicheng (2019) 2399; Qiankehezhicheng (2021) yiban217), the Guizhou Provincial Biology First-Class Subject Construction Project (GNYL (2017) 009).

Institutional Review Board Statement: Not applicable.

Informed Consent Statement: Not applicable.

Data Availability Statement: Not applicable.

Conflicts of Interest: The authors declare no conflict of interest.

\section{References}

1. Porkka, M.; Kummu, M.; Siebert, S.; Varis, O. From food insufficiency towards trade dependency: A historical analysis of global food availability. PLoS ONE 2013, 8, e82714. [CrossRef]

2. Aisawi, K.; Reynolds, M.P.; Singh, R.P.; Foulkes, M.J. The physiological basis of the genetic progress in yield potential of CIMMYT spring wheat cultivars from 1966 to 2009. Crop Sci. 2015, 55, 1749-1764. [CrossRef]

3. Battenfield, S.D.; Klatt, A.R.; Raun, W.R. Genetic yield potential improvement of semidwarf winter wheat in the Great Plains. Crop Sci. 2013, 53, 946-955. [CrossRef]

4. Sun, Y.; Wang, X.; Wang, N.; Chen, Y.; Zhang, S. Changes in the yield and associated photosynthetic traits of dry-land winter wheat (Triticum aestivum L.) from the 1940s to the 2010s in Shaanxi Province of China. Field Crops Res. 2014, 167, 1-10. [CrossRef]

5. Reynolds, M.; Bonnett, D.; Chapman, S.C.; Furbank, R.T.; Manès, Y.; Mather, D.E.; Parry, M.A.J. Raising yield potential of wheat. I. overview of a consortium approach and breeding strategies. J. Exp. Bot. 2011, 62, 439-452. [CrossRef]

6. Zhao, D.D.; Shen, J.Y.; Kun, L.; Liu, Q.R.; Li, Q.Q. Effects of irrigation and wide-precision planting on water use, radiation interception, and grain yield of winter wheat in the North China Plain. Agric. Water Manag. 2013, 118, 87-92.

7. Gao, F.M.; Ma, D.Y.; Yin, G.H.; Rasheed, A.; Dong, Y.; Xiao, Y.G.; Xia, X.C.; BU, X.X.; He, Z.H. Genetic progress in grain yield and physiological traits in Chinese wheat cultivars of southern Yellow and Huai Valley since 1950. Crop Sci. 2017, 57, 760-773. [CrossRef]

8. Liu, C.; Jia, Y.; Zhang, J.; Sun, P.; Li, J.; Li, P.; Shi, S. Effects of sowing patterns and irrigation amount on dry matter and yield of spring wheat. J. Triticeae Crops 2019, 39, 728-737.

9. Ali, S.; Xu, Y.; Ma, X.; Jia, Q.; Jia, Z. Farming practices and deficit irrigation management improve winter wheat crop water productivity and biomass through mitigated greenhouse gas intensity under semi-arid regions. Environ. Sci. Pollut. Res. 2021, 28, 27666-27680. [CrossRef]

10. Qin, X.; Zhang, F.; Liu, C.; Yu, H.; Cao, B.; Tian, S.; Liao, Y.; Siddique, K.H.M. Wheat yield improvements in China: Past trends and future directions. Field Crops Res. 2015, 177, 117-124. [CrossRef]

11. Austin, R.; Bingham, J.; Blackwell, R.D.; Evans, L.T.; Taylor, M. Genetic improvements in winter wheat yields since 1900 and associated physiological changes. J. Agric. Sci. 1980, 94, 675-689. [CrossRef]

12. Xiao, D.; Tao, F. Contributions of cultivars, management and climate change to winter wheat yield in the North China Plain in the past three decades. Eur. J. Agron. 2014, 52, 112-122. [CrossRef]

13. Zhang, X.; Wang, S.; Sun, H.; Chen, S.; Liu, X. Contribution of cultivar, fertilizer and weather to yield variation of winter wheat over three decades: A case study in the North China Plain. Eur. J. Agron. 2013, 50, 52-59. [CrossRef]

14. Zhang, J.; Sun, J.; Duan, A.; Wang, J.; Shen, X.; Liu, X. Effects of different planting patterns on water use and yield performance of winter wheat in the Huang-Huai-Hai plain of China. Agric. Water Manag. 2007, 92, 41-47. [CrossRef]

15. Li, Q.Q.; Zhou, X.B.; Chen, Y.H.; Yu, S.L. Water consumption characteristics of winter wheat grown using different planting patterns and deficit irrigation regime. Agric. Water Manag. 2012, 105, 8-12.

16. Klepeckas, M.; Janukaitien, I.; Vaguseviien, I.; Juknys, R. Effects of different sowing time to phenology and yield of winter wheat. Agric. Food Sci. 2020, 29, 346-358. [CrossRef]

17. Shah, F.; Coulter, J.A.; Ye, C.; BU, W. Yield penalty due to delayed sowing of winter wheat and the mitigatory role of increased seeding rate. Eur. J. Agron. 2020, 119, 126120. [CrossRef]

18. Abdelhadi, A.W.; El, A.; Bashir, M.A.; Hata, T. Evaluation of wheat bed planting system in irrigated vertisols of Sudan. Ama Agric. Mech. Asia Afr. Lat. Am. 2006, 37, 62-67.

19. Choudhury, B.U.; Bouman, B.; Singh, A.K. Yield and water productivity of rice-wheat on raised beds at New Delhi, India. Field Crops Res. 2007, 100, 229-239. [CrossRef]

20. Li, Q.; Bian, C.; Liu, X.; Ma, C.; Liu, Q. Winter wheat grain yield and water use efficiency in wide-precision planting pattern under deficit irrigation in North China Plain. Agric. Water Manag. 2015, 153, 71-76. [CrossRef]

21. Bian, C.Y.; Ma, C.J.; Liu, X.H.; Gao, C.; Liu, Q.R.; Yan, Z.X.; Ren, Y.J.; Li, Q.Q. Responses of winter wheat yield and water use efficiency to irrigation frequency and planting pattern. PLOS ONE 2016, 11, e0154673. [CrossRef]

22. Alam, M.S. Effect of sowing patterns and nitrogen rates on quality traits and yield of wheat. J. Environ. Sci. Nat. Resour. 2012, 5, 267-272. [CrossRef] 
23. Zhang, Z.; Zhou, X.B.; Chen, Y.H. Effects of irrigation and precision planting patterns on photosynthetic product of wheat. Agron. J. 2016, 108, 2322-2328. [CrossRef]

24. Castellanos-Navarrete, A.; Chocobar, A.; Cox, R.A.; Fonteyne, S.; Govaerts, B.; Jespers, N.; Kienle, F.; Sayre, K.D.; Verhulst, N. Yield and Yield Component, a Practical Guide for Comparing Crop Management Practices. J. Chem. Inf. Model 2013, 53, 1689-1699.

25. Koester, R.P.; Skoneczka, J.A.; Cary, T.R.; Diers, B.W.; Ainsworth, E.A. Historical gains in soybean (Glycine max Merr.) seed yield are driven by linear increases in light interception, energy conversion, and partitioning efficiencies. J. Exp. Bot. 2014, 65, 3311-3321. [CrossRef]

26. Shao, M.; Sun, L.; Zhao, K.; Xu, X.; Huang, L.; Wang, L.; Yan, L.; Ju, Z.C. Effects of different line spacing and seedling belt width on yield formation of broad-width fine sowing wheat. Agric. Biotechnol. 2020, 9, 29-33.

27. Barroso, J.; Genna, N.G. Effect of row spacing and seeding rate on Russian Thistle (Salsola tragus) in spring barley and spring wheat. Plants 2021, 10, 126. [CrossRef] [PubMed]

28. Brancourt-Hulmel, M.; Doussinault, G.; Lecomte, C.; Bérard, P.; Le Buanec, B.; Trottet, B. Genetic improvement of agronomic traits of winter wheat cultivars released in France from 1946 to 1992. Crop Sci. 2003, 43, 37-45. [CrossRef]

29. Beche, E.; Benin, G.; Silva, C.; Munaro, L.B.; Marchese, J.A. Genetic gain in yield and changes associated with physiological traits in Brazilian wheat during the 20th century. Eur. J. Agron. 2014, 61, 49-59. [CrossRef]

30. Del Pozo, A.; Matus, I.; Serret, M.D.; Araus, J.L. Agronomic and physiological traits associated with breeding advances of wheat under high-productive Mediterranean conditions. The case of Chile. Environ. Exp. Bot. 2014, 103, 180-189. [CrossRef] 